\title{
ANTIMICROBIAL ACTIVITY OF MORINGA OLEIFERA AGAINST MULTIDRUG-RESISTANT STAPHYLOCOCCUS AUREUS ISOLATED FROM RAW MILK
}

\author{
Tirado-Torres, D. ${ }^{1}$ - CHAN-Keb, C. A. ${ }^{2}$ - PÉrez-BALÁn, R. A. ${ }^{2}$ - AKe-CANChÉ, B. ${ }^{2}-$ \\ GÓMEZ-SOLANO, M. I. - ARAGÓN-GASTÉLUM, J. L. ${ }^{2}$ - GÓMEZ-LÓPEZ, I. ${ }^{3}$ - AGUIRRE-CRESPO, \\ F. J. ${ }^{2}$ - LÓPEZ-RAMOS, M. C. ${ }^{2}$ - GUTIÉRREZ-ALCÁNTARA, E. J. ${ }^{*}$ \\ ${ }^{I}$ Departamento de Ingeniería Civil, División de Ingenierías, Campus Guanajuato, Universidad \\ de Guanajuato, Av. Juarez N ${ }^{\circ} 77$, Col. Centro, Guanajuato, Gto., México \\ ${ }^{2}$ Facultad de Ciencias Químico-Biológica, Universidad Autónoma de Campeche Av. Agustín \\ Melgar S/N, Buena Vista, CP: 24039 Campeche, Cam., México \\ ${ }^{3}$ Centro Nacional de Metrología, Querétaro, México \\ *Corresponding author \\ e-mail: ejgutier@uacam.mx \\ (Received $11^{\text {th }}$ Sep 2018; accepted $28^{\text {th }}$ Nov 2018)
}

\begin{abstract}
The objective of the study was to evaluate the antimicrobial activity of aqueous and ethanolic Moringa oleifera leaf, stem and seed extracts against multidrug-resistant Staphylococcus aureus strains isolated from raw milk in Hidalgo Mexico in 2017. The conventional method was used to identify and isolate $S$. aureus. All isolates were screened for antibiotic sensitivity to 12 antibiotics using the diskdiffusion method, in order to select twenty multidrug-resistant strains. The antimicrobial activity of the M. oleifera leaf, stem and seed extracts (aqueous and ethanolic) was tested using the disk-diffusion agar method, with penicillin used as a positive control. Sixty-five S. aureus strains were isolated from $56 \%$ of the raw milk sample, with an average count of $4.5 \times 10^{5} \mathrm{CFU} / \mathrm{ml}$, this is considered as a potential public health risk. All the S. aureus strains exhibited resistance to at least two antibiotics. Sixty-five strains exhibited resistance to penicillin and ampicillin. In contrast, all showed sensitivity to ciprofloxacin. Ethanol extract exhibited a higher degree of antimicrobial activity compared to the aqueous extracts and penicillin. This reveals that the leaves, stems and seeds of $M$. oleifera could be an alternative for the control of infections caused by $S$. aureus in humans and cows with mastitis.
\end{abstract}

Keywords: foodborne pathogens, natural antimicrobial, bacteria, resistance, antibiotics

\section{Introduction}

Raw milk is an ideal growth medium for different microorganisms, as it is considered a vehicle for Staphylococcus aureus (S. aureus) infection in humans (Zecconi and Hahn, 2000). This foodborne pathogen is considered as one of the world's leading causes of disease outbreaks related to food consumption and is responsible for a variety of manifestations and diseases (Jamali et al., 2014). Although the precise number of Staphylococcal infections outbreaks is unknown in Mexico, previous studies have indicated that raw milk and dairy products manufactured from raw milk play an important role in outbreaks in humans (Rania et al., 2013; Basanisi et al., 2017). The contamination of milk and milk products with this pathogenic bacteria is mainly caused by the processing and handling of cows with mastitis in unhygienic environments (Thaker et al., 2013).

In Mexico, the production of bovine milk reached 11,707,494 tons in 2016, of which, 14,973 tons was produced in the municipality of Francisco I. Madero (SAGARPA, 
2016). As S. aureus is capable of acquiring antibiotic resistance determinants, its isolates often exhibit resistance to multiple classes of antimicrobial agents (Rybak and Laplante, 2005). Multiresistant $S$. aureus emerged decades ago due to the widespread and often inappropriate use of antibiotics in livestock (Mehli et al., 2017). The trend of rising antibiotic resistance continues despite the restrictions imposed on its use, both clinically and in food production (EFSA, 2009; NFSA, 2018). Resistant bacteria can be transmitted to humans through food, particularly that of animal origin and/or consumed raw (Phillips et al., 2004), and is a growing public health problem.

Increasing antibiotic resistance in pathogenic bacteria has led to growing demand for alternative safe and natural antimicrobials. The focus is currently on biologically active components isolated from plant species, such as Moringa oleifera (M. oleifera) (Arora and Onsare, 2014), used in food or herbal medicine, as these may provide a new source of antibacterial compounds (Gutiérrez-Alcántara et al., 2015).

M. oleifera is reported to have an antimicrobial effect on pathogenic bacteria (Brilhante et al., 2015; Peixoto et al., 2011; Viera et al., 2010). The antimicrobial properties of $M$. oleifera have been attributed to different parts of the plant, such as the leaves, seeds, pods and stems (Ferreira et al., 2011; Arora et al., 2013). In addition, studies conducted on this plant have revealed promising anti-inflammatory (Ezeamuzie et al., 1996), pro-coagulant (Nkurunziza et al., 2009), flocculant (in water treatments) (Beltrán-Heredia and Sánchez-Martín, 2009), detoxifying, immune boosting, and antiparasitic activity (Thilza et al., 2010), for the treatment of diarrhea and skin infections (Farooq et al., 2012). Moreover, it is rich in nutrients and has been used in different products such as oils, foods, condiments and medicine (Viera et al., 2010). However, less extensive research has been conducted on the antimicrobial effects of M. oleifera on multidrug resistant pathogenic strains. Currently there are no studies focused on analyzing the effect of the leaf, seed and stems together of $M$. oleifera, previously good results have been observed separately (Brilhante et al., 2015; Lar et al., 2011). The objective of the present study was to evaluate the antimicrobial activity of aqueous and ethanolic $M$. oleifera leaf, stem and seed extracts against multidrug-resistant $S$. aureus strains isolated from raw milk.

\section{Materials and methods}

\section{Collection of samples}

A total of 100 bulk-tank milk samples (one liter per sample) were collected from between April and August 2017 from 4 farms located in the municipality of Francisco I. Madero, Mexico (Figure 1). One farm was located within the Universidad Politécnica de Francisco y Madero (UPFIM), while the other three farms were located approximately $3.5 \mathrm{~km}$ from the university. The four farms (A-B-C-D) had less than 7 Holstein cows each and the age ranged between 2-2.5 years.

The samples were placed in sterilized bags under aseptic conditions and transported in an icebox to the laboratory, where they were then analyzed no more than one hour after their purchase from the dairy farms.

\section{Isolation and detection}

The bacteriological method used for identifying and isolating $S$. aureus was performed according to Mehli et al. (2017), in which $10 \mathrm{~mL}$ of raw milk was aseptically 
removed from each sample, placed in bags containing $90 \mathrm{~mL}$ of sterile peptone water (1.0 $\mathrm{g}$ bacteriological peptone and $8.5 \mathrm{~g} \mathrm{~L}-1$ sodium chloride) (Bioxon, the State of Mexico, Mexico), and homogenized manually for $2 \mathrm{~min}$. Ten-fold dilutions were made using sterile peptone water, after which the appropriate dilutions $(0.1 \mathrm{~mL})$ were spread on Baird-Parker agar supplemented with 1\% egg yolk tellurite emulsion (Bioxon, Estado de Mexico, Mexico). The plates were were placed in an incubator (Labtech LIB$150 \mathrm{M}$, USA) for $24-48 \mathrm{~h}$ at $37^{\circ} \mathrm{C}$.

Suggestive colonies of $S$. aureus (black, shining, and convex, with a $1.0-1.5 \mathrm{~mm}$ diameter and surrounded by a clear zone) were selected for seeding in tubes containing Brain Heart Infusion (Bioxon, the State of Mexico, Mexico), which were then incubated for $35^{\circ} \mathrm{C}$ for $24 \mathrm{~h}$. The presumptive strains of $S$. aureus were confirmed using coagulase, catalase, DNase, acetoin production and maltose fermentation tests (Saka and Terzi, 2018). All strains were also tested for the presence of staphylococcal enterotoxin using a commercial ELISA test kit (3M Tecra Code: FSA1156, New South Wales, Australia). The confirmed $S$. aureus strains were then preserved at $3-5^{\circ} \mathrm{C}$ for subsequent study.

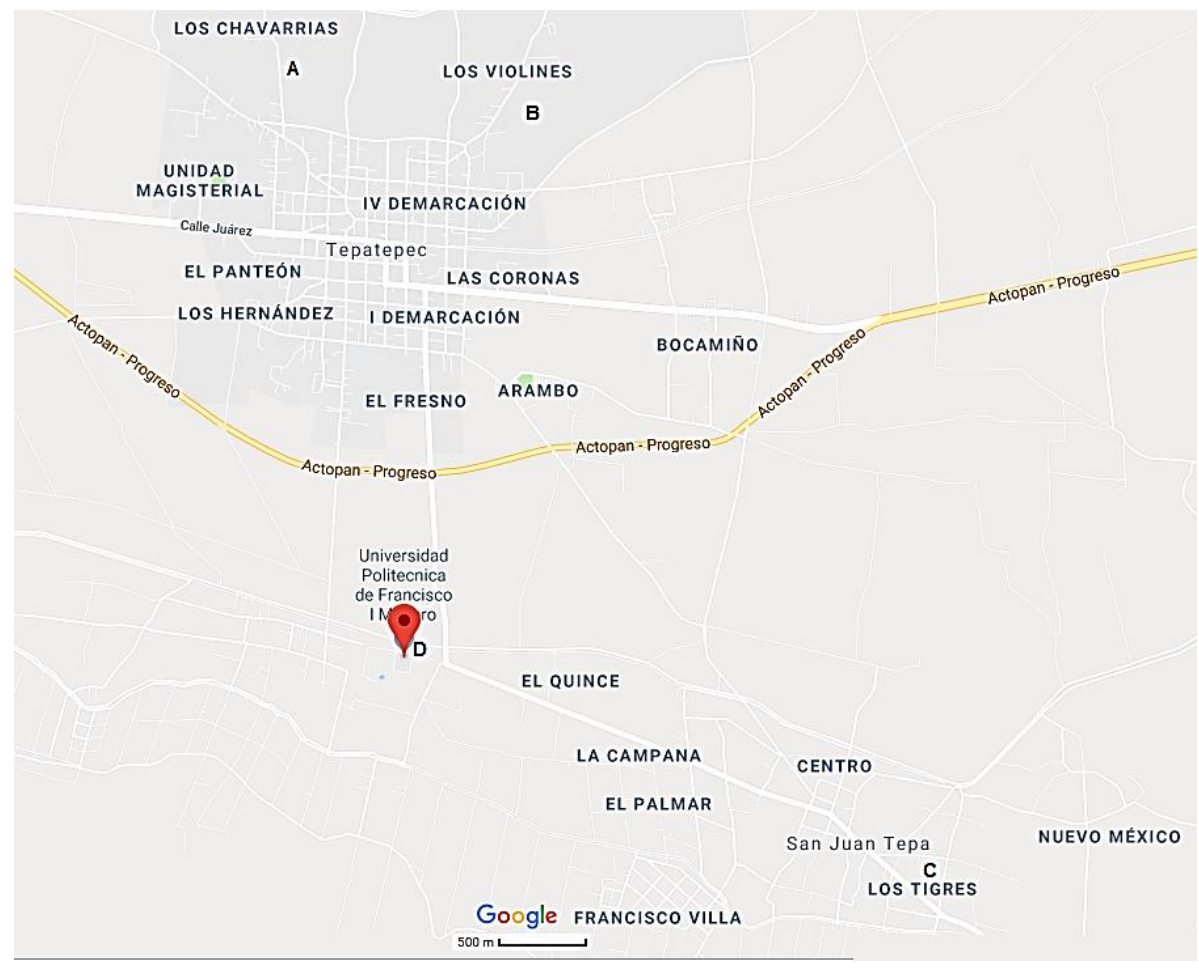

Figure 1. Location of the study areas

\section{Antibiotic susceptibility testing}

All S. aureus isolates were screened for antibiotic sensitivity to 12 different antibiotics using the disk-diffusion method on Muller-Hinton agar (Oxoid) with commercially available disks (Oxoid) in accordance with the Clinical and Laboratory Standards Institute (CLSI, 2014). The following antimicrobial agents were tested: ampicillin $(10 \mu \mathrm{g} / \mathrm{mL})$; cefalotin $(30 \mu \mathrm{g} / \mathrm{mL})$; cefotaxim $(30 \mu \mathrm{g} / \mathrm{mL})$; ciprofloxacin $(5$ $\mu \mathrm{g} / \mathrm{mL})$; clindamycin $(30 \mu \mathrm{g} / \mathrm{mL})$; dicloxacillin $(1 \mu \mathrm{g} / \mathrm{mL})$; erythromycin $(15 \mu \mathrm{g} / \mathrm{mL})$; gentamicin $(10 \mu \mathrm{g} / \mathrm{mL})$; penicillin $(10 \quad \mathrm{IU}) ;$ tetracycline $(30 \mu \mathrm{g} / \mathrm{mL})$; trimethoprim/sulfamethoxazole $(25 \mu \mathrm{g} / \mathrm{mL})$; and, vancomycin $(30 \mu \mathrm{g} / \mathrm{mL})$. The results 
were evaluated after incubation at $35^{\circ} \mathrm{C}$ for $24 \mathrm{~h}$, while the interpretations of antibiotic resistance were based on CLSI criteria (CLSI, 2014). For quality control, a reference strain of $S$. aureus (ATCC 25923) was used in the study.

\section{Plant material and extract preparation}

The extracts were obtained from M. oleifera specimens grown in Acapulco, the state of Guerrero, Mexico, and provided by the Universidad Autónoma de Guerrero. The age of the plant was two years.

The fresh leaves, stems and seeds were collected only once in May of 2017, they were cleaned and washed with water and dried in a heated chamber (Cole Parmer $399553-20$, I, USA) at $40^{\circ} \mathrm{C} / 24 \mathrm{~h}$.

The $M$. oleifera extracts were produced following a previously described method (Gutiérrez-Alcántara et al., 2015; Cruz-Gálvez et al., 2013). Briefly, all the materials were pulverized using an electric blender (Oster BPST02-B00-013, Mexico). About 100 $\mathrm{g}$ of the powdered materials (leaves, stems and seeds) were weighed and placed in sterile glass flasks, after which $900 \mathrm{~mL}$ of $70 \% \mathrm{v} / \mathrm{v}$ ethanol was added. The flasks were sealed and stored at room temperature for 7 days.

The extracts were filtered through Whatman No. 1 filter paper, with the ethanol extract then evaporated to dryness under reduced pressure using a rotary evaporator (BÜCHI, Vacuum AQ3 176 Controller V-800; Flawil, Switzerland) at $40^{\circ} \mathrm{C}$, leaving only the concentrated extract of the constituents of the powdered materials.

To prepare the aqueous extract, $100 \mathrm{~g}$ of the powdered materials (leaves, stems and seeds) was placed in a sterile glass flask, to which $900 \mathrm{~mL}$ of sterile distilled water was added. This was then heated to boiling point for $10 \mathrm{~min}$ and cooled to room temperature. The water was eliminated from the concentrate as described above, with the dried extracts then stored in sterile plastic bags at room temperature until use.

\section{Preparation of the extract solution}

A solution was prepared from each aqueous and ethanolic $M$. oleifera extract concentrate (produced from $5 \mathrm{~g}$ leaves, stems and seeds), using $100 \mathrm{ml}$ of distilled water (final extract concentration: $50 \mathrm{mg} \mathrm{mL}-1$ ). S. aureus ATCC 25923 strain was used as a quality control.

Inoculum preparation and inoculation. The antibacterial activity of $M$. oleifera leaf, stem and seed extracts was tested using the disk-diffusion agar method, as previously described (Gutiérrez-Alcántara et al., 2016), although with some modifications (it changed the Trypticase Soy Agar agar for a Muller Hinton and penicillin was used as a positive control). Briefly, antibiotic-resistant $S$. aureus strains isolated from raw milk were inoculated in tubes containing $3 \mathrm{~mL}$ trypticase soy broth (TSB, Bioxon, the State of Mexico, Mexico) and incubated at $35^{\circ} \mathrm{C}$ for $24 \mathrm{~h}$. The cultures were washed with sterile isotonic saline solution $(0.85 \% \mathrm{NaCl})$ via centrifuge at $3500 \mathrm{rpm}$ for $20 \mathrm{~min}$, with the pellets then resuspended in sterile peptone water at approximately $10^{9} \mathrm{CFU} / \mathrm{mL}$. A decimal dilution of these washed cultures was produced using isotonic saline solution to achieve a final approximate concentration of $8 \log \mathrm{CFU} / \mathrm{mL}$. A $100 \mu \mathrm{L}$ suspension was taken from the first dilution of each washed bacterial culture, inoculated on Mueller Hinton plates and extended over the agar (Bioxon, Estado de Mexico, Mexico). Filter paper (Whatman No. 5) disks were placed on the surface of each agar plate. Aliquots $(10 \mu \mathrm{L})$ of each extract were then placed on each disk (final dose per disc: $1 \mathrm{mg}$ extract), with isotonic saline solution used as a negative control and penicillin as a 
positive control. Each test was replicated three times. The plates were incubated for 24 $\mathrm{h}$ at $35^{\circ} \mathrm{C}$, and then examined for the presence of bacterial inhibition zones around the disk. The diameter $(\mathrm{mm})$ of any resulting inhibition zones was measured and the average diameter values were calculated for each extract.

\section{Statistical analysis}

Diameter of $S$. aureus growth was measured and expressed as means of percentaje growth inhibition of three replicates. Significant differences were calculated using statistica 8 program (StatSoft, Inc., Tulsa, version 8).

\section{Results and discussion}

\section{Prevalence of S. Aureus}

Sixty-five S. aureus strains were identified and isolated from $56 \%$ (Table 1) of the raw milk sample, with an average count of $4.5 \times 105 \mathrm{CFU} / \mathrm{ml}$. More than one staphylococci colony per plate were evaluated from only eight of the samples. Farm A presented 16 positive samples, while the Farm D presented 11 positive samples (the UPFIM farm).

Table 1. Prevalence of Salmonella in the sample of the farms

\begin{tabular}{c|c|c}
\hline Farm & Positive samples & Prevalence \% \\
\hline A $(n=25)$ & 16 & 64 \\
B $(n=25)$ & 13 & 52 \\
C $(n=25)$ & 16 & 64 \\
D $(n=25)$ & 11 & 44 \\
Total $(n=100)$ & 56 & $56 \%$ \\
\hline
\end{tabular}

The average $S$. aureus counts obtained in this research exceed the number of bacteria necessary $\left(1.0 \times 10^{5} \mathrm{CFU} / \mathrm{mL}\right)$ to produce sufficient enterotoxin in order to induce foodborne intoxication (Cupakova et al., 2012). Moreover, they increase the probability of the production of staphylococcal toxins that are resistant to both the boiling process carried out in homes when raw milk is bought and pasteurization processes (Tebaldi et al., 2008). The isolates obtained in this study should be considered as a potential public health risk, as this pathogen may enter the food chain.

The $S$. aureus frequency observed in the raw milk samples (56\%) coincides with the high $S$. aureus frequency reported in raw milk and dairy products in Greece and the USA (57.8\% and 62\%, respectively) (Papadopoulos et al., 2018; Haran et al., 2012). Furthermore, the results of this study are higher than those reported in Brazil by Fagundes et al. (2010) who observed a $7.3 \%$ frequency in raw milk samples, $6.7 \%$ in samples taken from individual cows, and $10.8 \%$ from bulk tank milk. In Italy, observed a $12.9 \%$ frequency in milk samples and dairy products (Basanisi et al., 2016). Riva et al. (2015) found that the prevalence of $S$. aureus was $9.1 \%$ in raw milk, while Normanno et al. (2007) reported a $17 \%$ contamination rate in milk and dairy products.

It should be noted both that other studies have reported prevalence rates of $66-86.1 \%$ (Saka and Terzi, 2018; Rania et al., 2013; Freitas et al., 2015; Rola et al., 2015), and that other authors have also reported the prevalence (13\% and $30 \%)$ of this pathogen in 
pasteurized milk (Akindolire et al., 2015; De Oliveira et al., 2011). The presence of these bacteria, after pasteurization, can be attributed to either the inefficacy of the thermal process or post-process contamination.

S. aureus is usually considered as a major cause of mastitis (Jamali et al., 2015). Certainly, many factors, such as improper bulk tank cleaning, dirty udders, an infected cow, dirty establishments and inappropriate hygiene conditions during milking, storage and manufacturing, are responsible for variations in the prevalence of $S$. aureus in dairy products, including milk (Roberson et al., 1998). For this reason, it is necessary to monitor animals state of health and improve hygienic conditions for milking, washing and the systematic disinfection of plants (Basanisi et al., 2017).

\section{Antimicrobial susceptibility}

All the $S$. aureus strains isolated from the raw milk exhibited resistance to at least two antibiotics. Sixty-five strains exhibited resistance to penicillin and ampicillin, followed by dicloxacillin. In contrast, all showed sensitivity to ciprofloxacin, while fifty-nine strains were sensitive to erythromycin (Table 2), fifty-three were sensitive to vancomycin, and fifty-three to tetracycline. The strains showed similar profile resistant to tetracycline and erythromycin, this may be possible because they act on protein synthesis. Ten strains presented intermediate resistance to cefotaxim. Similarly fourteen strains of $S$. aures presented intermediate resistance to cefalotin and clindamycine despite being from different groups.

Table 2. Counts for S. aureus strains exhibiting resistance (R), intermediate resistance (I), or sensitivity $(S)$ to 12 antibiotics

\begin{tabular}{c|c|c|c}
\hline Antibiotic & R & I & S \\
\hline Ampicillin & $65^{*}$ & 0 & 0 \\
Penicillin & 65 & 0 & 5 \\
Dicloxacillin & 40 & 20 & 23 \\
Cefotaxim & 32 & 10 & 20 \\
Cefalotin & 31 & 14 & 22 \\
Clindamycin & 29 & 14 & 25 \\
Gentamicin & 28 & 12 & 30 \\
Trimethoprim/Sulfamethoxazole & 20 & 15 & 53 \\
Vancomycin & 9 & 3 & 56 \\
Tetracycline & 8 & 1 & 59 \\
Erythromycin & 5 & 1 & 65 \\
Ciprofloxacin & 0 & 0 & \\
\hline
\end{tabular}

*strain counts

The results of this study are similar to those obtained from research conducted in China (Yang et al., 2016), in which S. aureus strains isolated from bovine mastitis cases were resistant to penicillin (84.09\%). In Greece, the most frequently observed resistance was to penicillin (99.3\%) (Papadopoulos et al., 2018), while Jamali et al. (2015) observed resistance to penicillin $(47.4 \%)$ in strains isolated from raw milk and dairy products. The high percentage of $S$. aureus that is resistant to penicillin could be due to the widespread administration of this antimicrobial to control and treat infections found 
in dairy farms (Jamali et al., 2013). Lowy (2003) reported that staphylococcal resistance to penicillin is mediated by $\beta$-lactamase, an extracellular enzyme which is synthesized when $S$. aureus is exposed to $\beta$-lactam antibiotics.

Resistance to ampicillin was high in all strains (100\%), which is in accordance with the natural resistance of $S$. aureus $\beta$ - lactams induced by exposure to penicillins (Fish et al., 1995). Other studies have shown resistance to ampicillin (Bernardo et al., 2005; Chudobova et al., 2015; Thaker et al., 2013). The results obtained here for ciprofloxacin coincide with a study in which $S$. aureus strains isolated from raw milk and dairy products were sensitive to ciprofloxacin (100\%) (Jamali et al., 2015); moreover, Papadopoulos et al. (2018) reported that $97.09 \%$ of strains were sensitive to this antibiotic. In addition, strains isolated from clinical cases, raw milk and dairy product in both Mexico and India have been reported to be resistant to ciprofloxacin (MirandaNovales, 2011; Thaker et al., 2013). Vancomycin-sensitive $S$. aures has been isolated in Turkey and China (Rağbetli et al., 2016; Yang et al., 2016), while nine strains resistant to vancomycin were found in this study. This resistance is due to the acquisition of the van gene, which is transferred via a plasmid (Bustos-Martínez et al., 2006).

Strains of $S$. aureus that are resistant to erythromycin and tetracyclines but sensitive to gentamycin have been isolated from retail meat in Denmark (Tang et al., 2017), a profile which is different to that observed in the present study for $S$. aureus strains isolated from raw milk samples.

\section{In-vitro antimicrobial activity of M. oleifera}

The testing, conducted in this study, of the effect of the leaves, stems and seeds of $M$. oleifera on the twenty antibiotic-resistant $S$. aureus strains isolated from raw milk (previously seleccioned for being multiresistant to 12 antibiotics) revealed that all the strains were sensitive to the two extracts (Table 3).

Table 3. Average diameter values of M. oleifera extract produced with two solvents versus antibiotic-resistant $S$. aureus strains and control strains

\begin{tabular}{cccc}
\hline & \multicolumn{3}{c}{ Zones of inhibition (Diameter in mm) } \\
\cline { 2 - 4 } Strains & Ethanolic extract & Aqueous extract & Penicillin \\
\hline 1 & $24 \pm 02$ & $23 \pm 04$ & $10 \pm 0.2$ \\
2 & $25 \pm 03$ & $22 \pm 04$ & $10 \pm 0.2$ \\
3 & $25 \pm 02$ & $23 \pm 02$ & $11 \pm 0.1$ \\
4 & $25 \pm 01$ & $23 \pm 01$ & $10 \pm 0.2$ \\
5 & $25 \pm 02$ & $23 \pm 08$ & $11 \pm 0.2$ \\
6 & $25 \pm 02$ & $21 \pm 04$ & $11 \pm 0.2$ \\
7 & $25 \pm 1.0$ & $23 \pm 01$ & $11 \pm 0.1$ \\
8 & $24 \pm 02$ & $23 \pm 06$ & $10 \pm 0.2$ \\
9 & $25 \pm 02$ & $22 \pm 04$ & $9 \pm 0.2$ \\
10 & $25 \pm 02$ & $23 \pm 03$ & $9 \pm 0.2$ \\
11 & $25 \pm 03$ & $23 \pm 03$ & $10 \pm 0.3$ \\
12 & $25 \pm 02$ & $21 \pm 01$ & $10 \pm 0.2$ \\
13 & $25 \pm 03$ & $23 \pm 06$ & $10 \pm 0.2$ \\
14 & $25 \pm 02$ & $23 \pm 08$ & $10 \pm 0.2$ \\
15 & $24 \pm 02$ & $21 \pm 06$ & $11 \pm 0.2$ \\
16 & $25 \pm 02$ & $23 \pm 06$ & $11 \pm 0.1$ \\
17 & $25 \pm 02$ & $23 \pm 04$ & $10 \pm 0.2$ \\
18 & $25 \pm 01$ & $22 \pm 02$ & $11 \pm 0.2$ \\
19 & $24 \pm 02$ & $23 \pm 02$ & $10 \pm 0.2$ \\
20 & $25 \pm 02$ & $21 \pm 02$ & $10 \pm 0.2$ \\
$*$ SA & $25 \pm 02$ & $22 \pm 02$ & $10 \pm 0.2$ \\
\hline
\end{tabular}

* SA (S. aureus ATCC 25923) 
The ethanolic extract presented the highest inhibitory effect against isolates from raw milk with halos of inhibition of $24.83 \mathrm{~mm}$ (mean). The mean of the halos of inhibition for the aqueous extract was $22.17 \mathrm{~mm}$, while the penicillin presented halos of inhibition of $9.77 \mathrm{~mm}$, and the halos of inhibition for the control strains were similar to the halos for the multiresistent strain. The strains 1,8 and 18 showed similar diameters with the extracts used, while the control strain showed similar diameters with the strain 2.

In addition, penicillin, ethanol and aqueous extract showed highly significant diference $(\mathrm{p}<0.0001)$.

Currently there are no studies focused on analyzing the effect of the leaf, seed and stems together of $M$. oleifera, previously good results have been observed separately (Brilhante et al., 2015; Lar et al., 2011).

The halos of inhibition found in this study $(21-25 \mathrm{~mm})$ coincide with a research in which M. oleifera seeds were studied for antimicrobial activity against Bacillus subtilis, Salmonella typhimurium, Enterobacter aerogenes, Pseudomonas aeroginosa, Escherichia coli, Vibrio cholerae and S. aureus (Ruttarattanamongkol and Petrasch, 2015). The above mentioned research found that $S$. aureus presented the maximum inhibition zone of 20.67 and $24.67 \mathrm{~mm}$. In contrast Peixoto et al. (2011) observed inhibition halos of up to $35 \mathrm{~mm}$ when challenging $S$. aureus with aqueous and ethanolic $M$. oleifera leaf extracts, but they also showed halos de inhibicion de 21-25 mm against Vibrio parahaemolyticus and Enterococcus. Some authors have attributed the antibacterial effect of the leaves to the presence of saponine, tannic, phenolic and alkaloid phytoconstituents (Doughari et al., 2007).

Working on the same plant species, Bukar et al. (2010) demonstrated the antibacterial activity of ethanolic extract of its seed, via the agar well diffusion method, against S. aureus, Salmonella typhi and E. coli. The activity of the two extracts was compared to a standard antibiotic (penicillin), as this antibiotic showed low efficiency in the previously isolated resistance profiles for the $S$. aureus strains. However, the two $M$. oleifera stem, leaf and seed extracts (ethanolic and aqueous) exhibited higher antibacterial activity compared to penicillin.

The ethanolic extract has been shown to present antimicrobial properties against $S$. aureus, with the findings of this research differing from Brilhante et al. (2015) who reported low antimicrobial effectiveness in ethanol extracts of $M$. oleifera pods, leaves, stems and seeds against Vibrio spp. strains, as well as no effect against E. coli. Furthermore, the results of the present study concur with those reported previously by other researchers in an evaluation of the antimicrobial effect of $M$. oleifera seed extracts against non-antibiotic resistant S. aureus (Viera et al., 2010; Ruttarattanamongkol and Petrasch, 2015).

The aqueous extract used in the present study presented inhibition halos of 22.17 $\mathrm{mm}$, which concurs with the results reported previously by research which evaluated the antimicrobial effect of aqueous $M$. oleifera seed extract against $S$. aureus, Vibrio cholerae and E. coli isolated from shrimp samples, observing inhibition halos of 19-25 $\mathrm{mm}$ (Viera et al., 2010).

While Lar et al. (2011) reported that the aqueous extract of M. oleifera seeds had no effect on E. coli, Shigella flexneri and S. typhi, appreciable antimicrobial activity was demonstrated by ethanolic seed extract on the same bacteria.

Similarly Kalpana et al. (2013) found antimicrobial activity using ethanolic extract of leaves of $M$. oleifera against $S$. aureus with diameters of 10-15 mm. 
The antimicrobial activity of $M$. oleifera has been attributed to antimicrobial peptides and bioactive compounds (Prasad and Elumalai, 2011). Wang et al. (2016) state that 4$(\alpha$-L-rhamnopyranosyloxy) benzyl isothiocyanate, methyl N-4-( $\alpha$-Lrhamnopyranosyloxy) benzyl carbamate, and 4 - $(\beta$-D-glucopyranosyl-1 $\rightarrow 4-\alpha-\mathrm{L}-$ rhamnopyranosyloxy)-benzyl thiocarboxamide are the three compounds of $M$. oleifera seed that present potent antibacterial activity against some pathogens.

Specifically, the compound 4-( $\alpha$-L-rhamnopyranosyloxy) benzyl isothiocyanate was found to inhibit the growth of $S$. aureus (Galuppo et al., 2013).

Almost all parts of the $M$. oleifera plant have an antimicrobial effect. In a previous study, Zaffer et al. (2014) found that the aqueous extract of M. oleifera bark presented high activity against $S$. aureus, while Devi et al. (2011) demonstrated the antibacterial activity of methanolic $M$. oleifera bark extract against Bacillus spp. and S. aureus.

In India, Devendra et al. (2011) demonstrated that chloroform M. oleifera leaf extract inhibits the growth of S. aureus and Streptococcus pyogenes, with halos of inhibition of 6.2 and $6.0 \mathrm{~mm}$, these diameters were lowest than ours. Nevertheless, Moyo et al. (2012) used water extract of $M$. oleifera and they did not show any antimicrobial activity against $S$. aureus, this differ with our results. Our findings also differ with that report by Singh et al. (2013), who reported that the ethanolic and aqueous extracts had low activity against the same pathogen.

It has also been shown that the $M$. oleifera flower has an antimicrobial effect against strains of $V$. cholerae and E. coli (Brilhante et al., 2015), an antibacterial property of $M$. oleifera flowers that has been attributed to a substance called pterygospermin (Anwar et al., 2007). Many studies have suggested that different crude extracts obtained from different $M$. oleifera tissues present antibacterial activities against both Gram-negative and Gram-positive bacteria (Wang et al., 2016; Bukar et al., 2010; Brilhante et al., 2015; Peixoto et al., 2011). Differences in polarity among the various solvents (methanol, ethanol, chloroform, water, petroleum ether, and ethyl acetate) may be responsible for the differences in the solubility of plant active principles, hence the variation in the degree of antimicrobial activity (Patel et al., 2018).

This study has shown that $S$. aureus strains resistant to multiple antibiotics are commonly found in the raw milk sold in the municipality of Francisco I. Madero, constituting a serious public health risk for the region's population. The most effective antibiotics against $S$. aureus were found to be ciprofloxacin, erythromycin and tetracycline.

The indiscriminate use of antibiotics for prophylactic and other therapeutic purposes could be the reason for the increased antimicrobial resistance of $S$. aureus.

Ethanol extract exhibited a higher degree of antimicrobial activity compared to the aqueous extracts and penicillin. This reveals that the leaves, stems and seeds of $M$. oleifera could be an alternative for the control of infections caused by $S$. aureus in humans and cows with mastitis.

Future studies will need to evaluate the antibacterial effect of $M$. oleifera leaf, stem and seed extract against other multidrug resistant-strains, such as E.coli, Salmonella, Shigella, Listeria monocytogenes, and V. cholerae.

Acknowledgements. The authors are grateful to the Universidad Politécnica de Francisco I. Madero for the financial support provided to this study. 


\section{REFERENCES}

[1] Akindolire, M. A., Babalola, O. O., Ateba, C. N. (2015): Detection of Antibiotic Resistant Staphylococcus aureus from Milk: A Public Health Implication. - Int J Environ Res Public Health 12(9): 10254-10275.

[2] Anwar, F., Latif, S., Ashraf, M., Gilani, A. H. (2007): Moringa oleifera: a food plant with multiple medicinal uses. - Phytother Res 21(1): 17-25.

[3] Arora, D. S., Onsare, J. G. (2014): In vitro antimicrobial evaluation and phytoconstituents of moringa oleífera pod husks. - Ind Crops Prod 52(1): 125-135.

[4] Arora, D. S., Onsare, J. M., Kuar, H. (2013): Bioprospecting of Moringa (Moringaceae): microbiological perspective. - J Pharmacogn Phytochem 1(6): 193-215.

[5] Basanisi, M. G., La Bella, G., Nobili, G., Franconieri, I., La Salandra, G. (2017): Genotyping of methicillin-resistant Staphylococcus aureus (MRSA) isolated from milk and dairy products in South Italy. - Food Microbiol 62: 141-146.

[6] Beltrán-Heredia, J., Sánchez-Martín, J. (2009): Improvement of water treatment pilot plant with Moringa oleifera extract as flocculant agent. - Environ Technol 30(6): 525534.

[7] Bernardo, W. L., Boriollo, M. F., Gonçalves, R. B., Höfling, J. F. (2005): Staphylococcus aureus ampicillin-resistant from the odontological clinic environment. - Rev Inst Med Trop Sao Paulo 47(1): 19-24.

[8] Brilhante, R. S. N., Sales, J. A., De Souza Sampaio, C. M., Barbosa, F. G., De Araújo, N. P. M., De Melo Guedes, G. M. (2015): Vibrio spp. from Macrobrachium amazonicum prawn farming are inhibited by Moringa oleifera Extracts. - Asian Pac J Trop Me 8(11): 919-922.

[9] Bukar, A., Uba, A., Oyeyi, I. (2010): Antimicrobial profile of Moringa Oleifera Lam. Extracts against some foodborne microorganisms. - Bayero Journal of Pure and Applied Sciences 3(1): 43-48.

[10] Bustos-Martínez, J. A., Hamdan-Partida, A., Gutiérrez-Cárdenas, M. (2006): Staphylococcus aureus: la reemergencia de un patógeno en la comunidad. - Rev Biomed 17: 287-305.

[11] Chudobova, D., Dostalova, S., Blazkova, I., Michalek, P., Ruttkay-Nedecky, B., Sklenar M. (2014): Effect of Ampicillin, Streptomycin, Penicillin and Tetracycline on Metal Resistant and Non-Resistant Staphylococcus aureus. - Int J Environ Res Public Health 1911(3): 3233-3255.

[12] CLSI. (Clinical and Laboratory Standards Institute) (2014): Performance Standars for Antimicrobial Susceptibility Testing. Nineteen Informational Supplement. - M100-S19 Wayne, Pa, USA.

[13] CLSI. (Clinical and Laboratory Standards Institute) (2014): Performance Standars for Antimicrobial Susceptibility Testing. Twenty-four Informational Supplement. - Tech. Rep. M100-S24. Wayne, Pa, USA.

[14] Cruz-Gálvez, A. M., Gómez-Aldapa, C. A., Villagomez-Ibarra, J. R., ChavarríaHernández, N., Rodríguez-Baños, J., Rangel-Vargas, E., Castro-Rosas, J. (2013): Antibacterial effect against foodborne bacteria of plants used in traditional medicine in central Mexico: Studies in vitro and in raw beef. - Food Con 32: 289-295.

[15] Cupakova, S., Pospisilova, M., Karpiskova, R., Janstova, B., Vorlova, L. (2012): Microbiological quality and safety of goat's milk from one farm. - Acta Univ Agric Fac Agron 60(6): 33-38.

[16] De Oliveira, L. P., Soares, B. L. S., Silva, V. C., Cirqueira, M. G. (2011): Study of Staphylococcus aureus in raw and pasteurized milk consumed in the Reconcavo area of the State of Bahia, Brazil. - J Food Process Technol 2(6): 1-5.

[17] Devendra, B. N, Srinivas, N., Talluri, V. S. S. L. P., Latha, P. S. (2011): Antimicrobial activity of Moringa oleifera Lam., leaf extract, against selected bacterial and fungal strains. - International Journal of Pharma and Bio Sciences 2(3): 13-18. 
[18] Devi, G. S., Priya, V., Abiramasundari, P., Jeyanthi, P. G. (2011): Antibacterial activity of the leaves, bark, seed and flesh of Moringa oleifera. - Int J Phar Sci and Res 2(8): 2045-2049.

[19] Doughari, J., Pukuma, M., De, N. (2007): Antibacterial effects of Balanites aegyptiaca L. Drel. and Moringa oleifera Lam. On Salmonella typhi. - African Journal of Biotechnology 6(19): 2212-2215.

[20] EFSA. European Food Safety Authority (2009): Joint scientific report of ECDC, EFSA and EMEA on meticillin resistant Staphylococcus aureus (MRSA) in livestock, companion animals and foods. - EFSA-Q-2009-00612. EFSA Scientific Report 301: 110.

[21] Ezeamuzie, I. C., Ambakederemo, A. W., Shode, F. O., Ekwebelem, S. C. (1996): Antiinflammatory effects of Moringa oleifera root extract. - Pharm Biol 34(3): 207-212.

[22] Fagundes, H., Barchesi, L., Filho, A. N., Ferreira, M. L., Fernandes Oliveira, C. A. (2010): Occurrence of Staphylococcus aureus in raw milk produced in dairy farms in São Paulo state, Brazil. - Braz J Microbiol 41(2): 376-380.

[23] Farooq, F., Rai, M., Tiwari, A., Khan, A. A., Farooq, S. (2012): Medicinal properties of Moringa oleifera: An overview of promising healer. - J Med Plants Res 6(27): 43684374.

[24] Ferreira, R. S., Napoleão, T. H., Santos, A. F. S., Sá, R. A., Carneiro-da-Cunha, M. G., Morais, M. M. (2011): Coagulant and antibacterial activities of the water-soluble seed lectin from Moringa oleifera. - Lett Appl Microbiol 53(2): 186-192.

[25] Fish, D. N., Piscitelli, S. C., Danziger, L. H. (1995): Development of resistance during antimicrobial therapy: a review of antibiotic classes and patient characteristics in 173 studies. - Pharmacotherapy 15(3): 279-291.

[26] Freitas, J. A., Oliveira, J. P., Galinda, G. A. R. (2005): Avaliação da qualidade higiênico sanitária do leite exposto ao consumo na região metropolitana de Belém-PA. - Rev Inst Adolfo Lutz 64(2): 212-218.

[27] Galuppo, M., Nicola, G. R., Iori, R., Dell'Utri, P., Bramanti, P. (2013): Antibacterial activity of glucomoringin bioactivated with myrosinase against two important pathogens affecting the health of long-term patients in hospitals. - Molecules 18(11): 14340-14348.

[28] Gutiérrez-Alcántara, E. J., Rangel-Vargas, E., Gómez-Aldapa, C. A., Falfan-Cortes, R. N., Rodríguez-Marín, M. L., Godínez-Oviedo, A. (2015): Antibacterial effect of roselle extracts (Hibiscus sabadariffa), sodium hypochlorite and acetic acid against multidrugresistant Salmonella strains isolated from tomatoes. - Lett Appl Microbio 62: 177-184.

[29] Gutiérrez-Alcántara, E. J., Gómez-Aldapa, C. A., Román-Gutiérrez, A. D., RangelVargas, E., González-Olivares, L. G., Castro-Rosas, J. (2016): Antimicrobial activity of roselle hibiscus sabdariffa calyx extracts on culture media and carrots against multidrugresistant salmonella strains isolated from raw carrots. - J Food Saf 35(4): 450-458.

[30] Haran, K. P., Godden, S. M., Boxrud, D., Jawahir, S., Bender, J. B., Sreevatsan, S. (2012): Prevalence and characterization of Staphylococcus aureus, including methicillinresistant Staphylococcus aureus, isolated from bulk tank milk from Minnesota dairy farms. - J Clin Microbiol 50(3): 688-695.

[31] Jamali, H., Radmehr, B., Thong, K. L. (2013): Prevalence, characterisation, and antimicrobial resistance of Listeria species and Listeria monocytogenes isolates from raw milk in farm bulk tanks. - Food Cont 34(1): 121-125.

[32] Jamali, H., Radmehr, B., Ismail, S. (2014): Prevalence and antibiotic resistance of Staphylococcus aureus isolated from bovine clinical mastitis. - Journal of Dairy Science 97: 2226-2230.

[33] Jamali, H., Paydar, M., Radmehr, B., Ismail, S., Dadrasnia, A. (2015): Prevalence and antimicrobial resistance of Staphylococcus aureus isolated from raw milk and dairy products. - Food Cont 54: 383-388. 
[34] Kalpana, S., Moorthi, S., Sushila kumari. (2013): Antimicrobial activity of different extracts of leaf of Moringa oleifera (Lam) against gram positive and gram negative bacteria. - Int. J. Curr. Microbiol. App. Sci 2(12): 514-518.

[35] Lar, P. M., Ojile, E. E., Dashe, E., Oluoma, J. N. (2011): Antibacterial activity of Moringa oleifera seed extracts on some gram negative bacterial isolates. - African journal of natural sciences 14: 57-62.

[36] Lowy, F. D. (2003): Antimicrobial resistance: the example of Staphylococcus aureus. - J Clin Invest 111(9): 1265-1273.

[37] Mehli, L., Hoel, S., Thomassen, G. M. B., Jakobsen, A. N., Karlsen, H. (2017): The prevalence, genetic diversity and antibiotic resistance of Staphylococcus aureus in milk, whey, and cheese from artisan farm Dairies. - International Dairy Journal 65: 20-27.

[38] Miranda-Novales, M. G. (2011): Antimicrobial resistance in Staphylococcus aureus in Mexico. - Bol Med Hosp Infant Mex 68(4): 242-249.

[39] Moyo, B., Masika, P. J., Muchenje, V. (2012): Antimicrobial activities of Moringa oleifera Lam leaf extracts. - African Journal of biotechnology 11(11): 2797-2802.

[40] NFSA. (2018): MRSA funnet hos storfe i Rogaland. Oslo, Norway: Norwegian Food Safety Authority (Accessed 23 march 2018). http://www.mattilsynet.no/dyr_og_dyrehold/produksjonsdyr/storfe/mrsa_funnet_hos_stor fe_i_rogaland.20524.

[41] Nkurunziza, T., Nduwayezu, J. B., Banadda, E. N., Nhapi, I. (2009): The effect of turbidity levels and Moringa oleifera concentration on the effectiveness of coagulation in water treatment. - Water Sci technol 59(8): 1551-1558.

[42] Normanno, G., La Salandra, G., Dambrosio, A., Quaglia, N. C., Corrente, M., Parisi, A. (2007): Occurrence, characterization and antimicrobial resistance of enterotoxigenic Staphylococcus aureus isolated from meat and dairy products. - Int J Food Microbiol 115(3): 290-296.

[43] Padla, E. P., Solis, L. T., Levida, R. M., Shen, C. C., Ragasa, C. Y. (2012): Antimicrobial isothiocyanates from the seeds of Moringa oleifera Lam. - Z Naturforsch C 67(11-12): 557-564.

[44] Papadopoulos, P., Papadopoulos, T., Angelidis, A. S., Boukouvala, E., Zdragas, A., Papa, A. (2018): Prevalence of Staphylococcus aureus and of methicillin-resistant S. aureus (MRSA) along the production chain of dairy products in north-western Greece. - Food Microbiol 69: 43-50.

[45] Patel, N., Mohan, J. S. S. (2018): Antimicrobial Activity and Phytochemical Analysis of Moringa oleifera Lam. Crude Extracts Against Selected Bacterial and Fungal Strains. International Journal of Pharmacognosy and Phytochemical Research 10(2): 68-79.

[46] Peixoto, J. R., Silva, G. C., Costa, R. A., De Sousa, F. J. R., Vieira, G. H., Filho, A. A. (2011): In vitro antibacterial effect of aqueous and ethanolic Moringa leaf extracts. Asian Pac J Trop Med 4(3): 201-204.

[47] Phillips, I., Casewell, M., Cox, T., De Groot, B., Friis, C., Jones, R. (2004): Does the use of antibiotics in food animals pose a risk to human health? A critical review of published data. - J Antimicrob Chemother 53(1): 28-52.

[48] Prasad, T. N., Elumalai, E. K. (2016): Biofabrication of Ag nanoparticles using Moringa oleifera leaf extract and their antimicrobial activity. - Asian Pac J Trop Biomed 2011 1(6): 439-442.

[49] Rağbetli, C., Parlak, M., Bayram, Y., Guducuoglu, H., Ceylan, N. (2016): Evaluation of Antimicrobial Resistance in Staphylococcus aureus Isolates by Years. - Interdiscip Perspect Infect Dis: 1-4.

[50] Rania, M. K., Mohamed, A. B., Salah, F. A. A. E. A. (2013): MRSA detection in raw milk, some dairy products and hands of dairy workers in Egypt, a mini-survey. - Food Cont 33: 49-53.

[51] Riva, A., Borghi, E., Cirasola, D., Colmegna, S., Borgo, F., Amato, E. (2015): Methicillin-Resistant Staphylococcus aureus in Raw Milk: Prevalence, SCCmec Typing, 
Enterotoxin Characterization, and Antimicrobial Resistance Patterns. - J Food Prot 78(6): 1142-1146.

[52] Roberson, J. R., Fox, L. K., Hancock, D. D., Gay, J. M., Besser, T. E. (1998): Sources of intramammary infections from Staphylococcus aureus in dairy heifers at first parturition. - J Dairy Sci 81(3): 687-693.

[53] Rola, J. G., Sosnowski, M., Ostrowska, M., Osek, J. (2015): Prevalence and antimicrobial resistance of coagulase-positivestaphylococci isolated from raw goat milk. - Small Rum Res 123: 124-128.

[54] Ruttarattanamongkol, K., Petrasch, A. (2015): Antimicrobial activities of Moringa oleifera seed and seed oil residue and oxidative stability of its cold pressed oil compared with extra virgin olive oil. - Songklanakarin J Sci Technol 37(5): 587-594.

[55] Rybak, M. J., Laplante, K. L. (2005): Community-associated methicillin-resistant. Staphylococcus aureus: a review. - Pharmacotherapy 25(1): 74-85.

[56] SAGARPA. (Secretaria de agricultura, Ganaderia, recursos naturales, Pesca y Alimentación) (2016): Producción annual. SIAP. Servicio de Información Agroalimentaria $\mathrm{y}$ pesquera $-\mathrm{y}$ Available at: http://infosiap.siap.gob.mx/anpecuario_siapx_gobmx/indexmpio.jsp. Accessed may 5, 2018.

[57] Saka, E., Terzi, G. G. (2018): Detection of Enterotoxin Genes and Methicillin-Resistance in Staphylococcus aureus isolated from Water Buffalo Milk and Dairy Products. - J Food Sci 83(6): 1716-1722.

[58] Tang, Y., Larsen, J., Kjeldgaard, J., Andersen, P. S., Skov, R., Ingmer, H. (2017): Methicillin-resistant and susceptible Staphylococcus aureus from retail meat in Denmark. - Int J Food Microbiol 249: 72-76.

[59] Tebaldi, V. M. R., Oliveira, T. L. C., Boari, C. A., Piccoli, R. H. (2008): Isolamento de coliformes, estafilococos e enterococos de leite cru provinientes de tanques de refrigeração por expansão comunitários: identificação, ação lipolítica e proteolítica. Ciênc Tecnol Aliment Campinas 28(3): 753-760.

[60] Thaker, H. C., Brahmbhatt, M. N., Nayak, J. B. (2013): Isolation and identification of Staphylococcus aureus from milk and milk products and their drug resistance patterns in Anand, Gujarat. - Vet World 6(1): 10-13.

[61] Thilza, I. B., Sanni, S., Zakari, A. I., Sanni, F. S., Muhammed, T., Musa, B. J. (2010): In vitro antimicrobial of water extract of Moringa oleifera leaf stalk on bacterial normally implicated in eye disease. - Acad Aren 2(6): 80-83.

[62] Viera, G. H., Mourão, J. A., Angelo, A. M., Costa, R. A., Vieira, R. H. (2010): Antibacterial effect (in vitro) of Moringa oleifera and Annona muricata against Gram positive and Gram negative bacteria. - Rev Inst Med Trop Sao Paulo 52(3): 129-132.

[63] Wang, L., Chen, X., Wu, A. (2016): Mini review on Antimicrobial Activity and Bioactive Compounds of Moringa oleifera. - Med Chem 6(9): 578-582.

[64] Yang, F., Wang, Q., Wang, X., Wang, L., Li, X., Luo, J. (2016): Genetic characterization of antimicrobial resistance in Staphylococcus aureus isolated from bovine mastitis cases in Northwest China. - Journal of Integrative Agriculture 15(12): 2842-2847.

[65] Zaffer, M., Ahmad, S., Sharma, R., Mahajan, S., Gupta, A., Agnihotri, R. K. (2014): Antibacterial activity of bark extracts of Moringa oleifera Lam. against some selected bacteria. - Pak J Pharm Sci 27(6): 1857-1862.

[66] Zecconi, A., Hahn, G. (2000): Staphylococcus aureus in raw milk and human health risk. - Bull. IDF 345: 15-18. 